\title{
Participation in planning and governance: closing the gap between satisfaction and expectation
}

\author{
Rob Weymouth * ${ }^{*}$ and Janette Hartz-Karp
}

\begin{abstract}
Background: Making and implementing decisions to improve long term sustainability, particularly in democratic countries, is a significant challenge. This is exacerbated when citizens' expectations of their relationship with government is significantly at odds with what they experience, since this is likely to further reduce their already low trust in government and its decision-making. Research in the USA has demonstrated a clear gap between citizens' expectations of their participation in government and their satisfaction with that participation. This finding inspired a research project in regional Western Australia to determine if a similar gap existed between citizens' expectations and experience of their relationship with government. Additionally, a public participation intervention was devised to determine whether the gap between citizens' expectations of, and experience with, governance could be reduced and whether the decisions made from such an intervention would be more implementable. To better reflect the partnership relationship citizens expected from government, 'deliberative democracy' initiatives were implemented to resolve the local government's budgeting challenges.

Results: The results demonstrated that a similar gap to that in the USA was present in Western Australia community and the sample populations used in the partnership interventions. Further, the citizens' experience of deliberative democracy substantially reduced the gap between their expectations and experience of government participation. These case studies also revealed the existence and details of the nature of this partnership relationship between citizens and government as well as between the citizens themselves. Moreover, the tough budgetary decisions they made were implemented without public outcry.

Conclusions: These case studies show a promising route to close the gap between citizen expectations and satisfaction with participation in government, as well as having the potential to increase the trust in government so necessary for advances in sustainability. Future research directions have been outlined to improve understanding of how these results could impact on sustainability efforts.
\end{abstract}

Keywords: Participatory budgeting, Arnstein gap, Deliberative democracy, Participation, Trust

\section{Plain English summary}

Achieving widespread sustainability will require high levels of trust in the good intentions and competency of governments by their people. Working against this is the good evidence that a gap exists between what sort of participation relationship people want with their governments and the sort of relationship that governments are delivering. This gap hampers the cooperation between citizens and government so necessary in a world

\footnotetext{
* Correspondence: Robert.weymouth@postgrad.curtin.edu.au

Curtin University Sustainability Policy Institute, Perth, Australia
}

currently grappling with the wicked problem of moving toward sustainability. This study established the generalisability of this disconnect outside the US and conducted an intervention through a case study to try and close this gap. Our paper showed that an intervention that delivered a partnership relationship between citizens and government during the allocation of a public budget was able to significantly close the gap. We discuss the practical designs and techniques that contributed to this type of participation relationship and suggest a link between dissatisfaction with participation relationships in government and the crippling loss of trust in governments

(c) The Author(s). 2019 Open Access This article is distributed under the terms of the Creative Commons Attribution 4.0 International License (http://creativecommons.org/licenses/by/4.0/), which permits unrestricted use, distribution, and 
worldwide. We finish by highlighting research directions that will exploit the advances made in this work.

\section{Introduction}

For decades, calls have been made for more effective public participation in planning, policy development and public service delivery [1]. Such calls are particularly pertinent to the journey toward greater sustainability globally [2] and locally [3, 4]. These appeals have not been heeded, despite the continuing decline in citizens trust and confidence in their democratic governments across the globe [5]. This study aims to further understand the role of public participation in influencing these public attitudes towards governance with the purpose of facilitating the implementation of sustainability.

There is general consensus that democracy, at its heart, is a system of government that requires participation from its citizens in the process of planning and executing governance [6]. The degree and nature of this participation varies in different democracies, from voting for representatives, to direct referendums, and in past centuries, the random selection of citizens to government positions [7].

There have also been a broad range of views about the appropriate level of participation: from the lack of general participation implicit in Plato's concept of philosopher kings; to the distrust of the motives and capability of the citizenry of the American Founding fathers [8]; and from delegate vs trustee representation systems [9]; to the modern desire for fuller participation and universal suffrage [10]. However, regardless of one's normative position on the ideal degree of participation in a democracy, an empirical approach is at least as important. This paper concerns itself with this very question: What sort of participation does the democratic public want and what are they getting?

The empirical approach to public participation, however is not free of contested conclusions. For example, using surveys and focus groups to understand attitudes about participation, Hibbing and Morse developed a concept called 'stealth democracy' [11]. The authors interpreted their results to indicate a dislike for political participation in the US public. This distaste was only balanced by the fear that by not being involved in politics would encourage corruption and advantage the political class, so people felt forced to be involved. Other researchers have critiqued this work from the normative perspective [12] and also methodologically - as being limited by the interpretation of the focus group results [13] and the shallow and contextual preferences expressed [14]. Other empirical studies have focussed on assessing the existing attitudes of large population samples (such as electoral and telephone surveys) toward different types of participation. Some results have attracted popular attention such as findings that more than half of Australian young people do not find democracy the preferred form of government [15].

Rather than broad studies about the status quo, the following study examined a direct intervention on a sample group to alter the 'business as usual' level of participation, then assessed its impact through surveys and in-depth interviews to deepen the understanding of the survey responses and explain any changes detected. Additionally, surveys of the broader population were conducted to enable population comparisons and to connect this research to that of the larger field. We present our attempt to further understand the role of public participation in influencing public attitudes towards governance in four steps, by:

1. Reviewing the normative and empirical literature on participation in governance.

2. Applying the "Arnstein Ladder" to measure the difference between expectations of participation and what's experienced (the "Arnstein gap").

3. Analysing the Arnstein gap data gathered before, during, and after an intervention in a Western Australian city-region.

4. Analysing the intervention data to further understand the partnership relationship and how the Arnstein Gap can be reduced to improve the relationship between the public and government; with suggestions for future research.

\section{The disparity between participation expectations and experience - the Arnstein gap}

When settling on the most appropriate way to assess participation attitudes in this situation, the Arnstein ladder was applied as the measurement tool. This standardised spectrum of participation (see Fig. 1) has been used by disparate researchers for diagnostic and prescriptive purposes [16-19]. The Arnstein ladder [20] was seminal in the evolution of thinking about the role of citizens in planning [1]. It provided an 8 point scale for assessing a citizen's expectations of participation in government had the potential to assess his/her experience in participation in governance. The ladder and its variants have been used particularly in the planning field $[19,21,22]$; as well as in business studies, health planning, international development and child education [23]. It has undergone additions [23, 24] bifurcation [25] and other variations, including into spectrums of public participation, oft used by public engagement practitioners and researchers [26, 27]. Some scholars have rejected the Arnstein ladder outright for being too limited and simplistic [23] or an inappropriate fusing of an empirical and normative scale [28]. Others criticised it for 


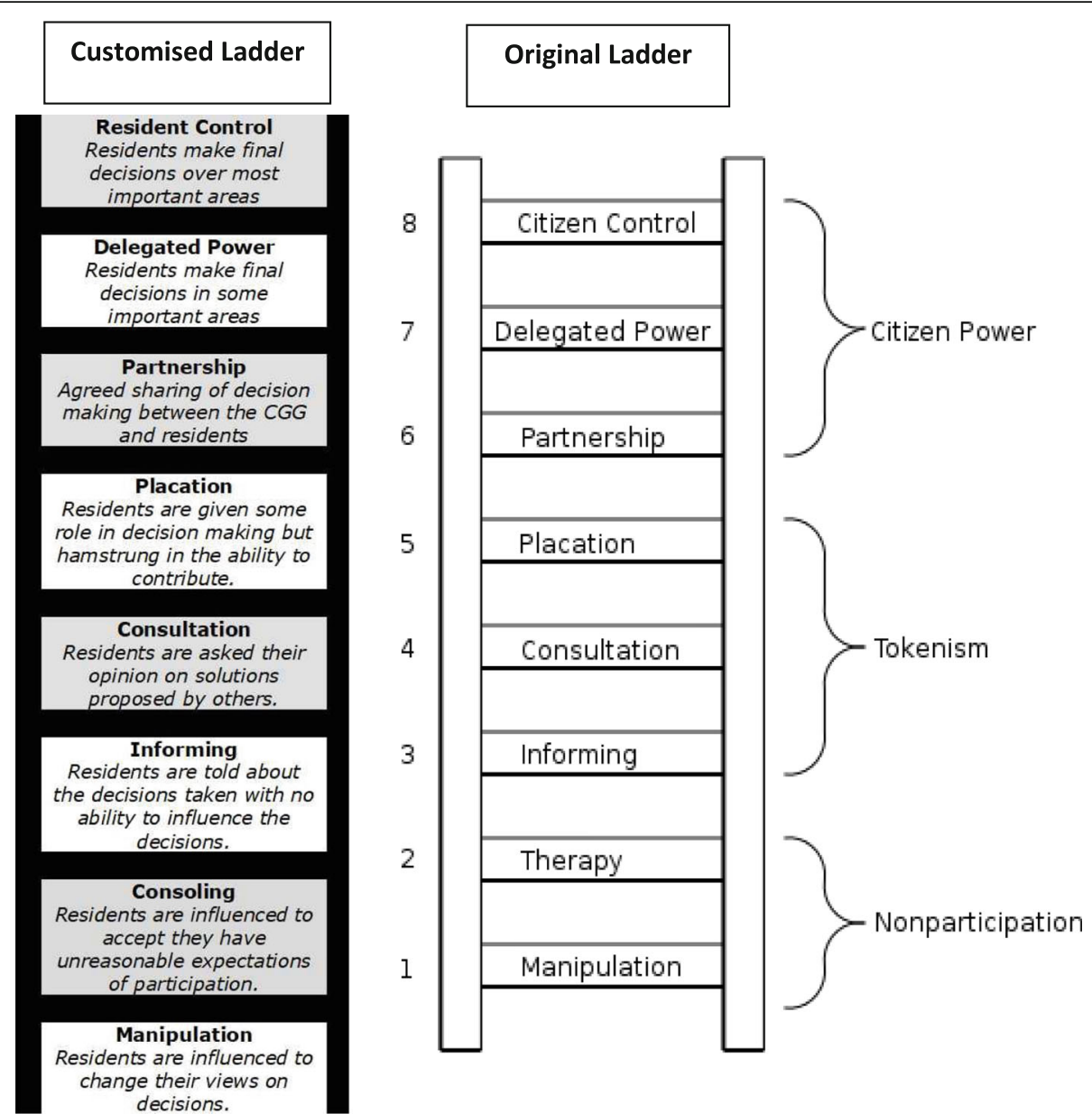

Fig. 1 customisation of the Arnstein Ladder in the CGG side-by-side with Arnstein's Original Ladder [20]

being too theoretical at the extremes of the spectrum and normatively offensive in the middle [29].

Understanding the strengths and limitations of the Arnstein Ladder, it was considered the most appropriate tool for this study. The normative critiques were less consequential since it was used to detect norms as well as empirical attitudes amongst citizens and government professionals. The strengths as an educative tool, providing clarity and common language, with a clear classification of government relationship types, was reinforced in pilot testing where subjects found it easy to understand. The extended range of participation processes described in the ladder assisted in this role as a descriptive and investigative tool [29]. While a ladder could culturally imply that rungs further up the ladder were in some way superior there was not any analytic judgement of superiority [30]. Theoretically, the framing language of the Arnstein ladder represented a Foucaultian oppositional stance, whereas the Habermasian collaborative approach underlay the deliberative democracy intervention implemented in this study. This oppositional approach was selected purposefully to avoid the presumption of collaboration in other models [31] which could have tilted preferences. Finally, the ladder was selected as it enabled cross comparison with similar surveys used where institutionalised power exists in a nearly dichotomous relationship with citizens [32].

The most significant participation work to date used the Arnstein ladder to measure quality deficits in public involvement in transport and energy infrastructure projects [33]. Both participants in the public consultations and infrastructure professionals were administered the same keypad survey. In reviewing the results from 3000 participants across six states in USA from 2003 to 2015, the authors [34] noted several outcomes pertinent to the following research:

- Citizens' preference was not for a relationship of domination of their government but of "partnership".

- Citizens' expectation of participation was not currently being met by the existing system, which 
they judged as engaging in a 'consultation' relationship with them. Both citizens and professionals found the actual participation relationship was falling short of what they expected and the authors named this the 'Arnstein Gap'.

- Citizens and subject matter professionals both had the same preference for an ideal relationship of 'partnership' with government, but they differed in their assessment of the participation being realised the professionals being more optimistic in their assessment of current levels of participation (called 'professional conceit' by the authors).

Numerous questions could be raised about these conclusions that are also relevant to our current study and we include these here with our attached observations:

- Were respondents' assessments of the current level of participation accurate, i.e. informed and unbiased? It would appear so since to a certain degree the respondents assessments triangulate with that of the professionals (who may or may not be more informed and 'accurate') and both agree there is a gap between the ideal and the reality.

- Did participants understand the meaning of each step on the ladder? Although respondent interpretation is a constant danger in surveys [13], it was mitigated in the following research by providing a clear explanation of each level under each rung's label (see Fig. 1).

- Did the ladder culturally encourage participants to select higher levels as 'better'?

The following research results, quantitative and qualitative, did not support this notion (i.e. the respondents' ideal level, although elevated, was not in the top two levels of the ladder).

- Finally, did citizens have a faulty or unrealistic expectation of participation in government? This questions is a return to a normative question which becomes moot in this empirical study: If the public perceived that its government was failing to meet its expectations of participation, then this performance dissatisfaction would be important and consequential, whether it was reasonable or not.

To extend and deepen our understanding of the Arnstein gap, the following research pursued 3 additional questions:

a) Can the finding of a gap be generalised from the United States populations researched to Australians?

b) Can this gap be influenced and reduced by implementing a participatory intervention more in line with citizen expectations; and would such public participation enable more implementable decisions?

c) Would different interventions result in different effects?

\section{Generalisability of Arnstein gap}

So how generalisable is the gap in other contexts? As far as we can tell the gap between citizen expectations and their experience of participation in governance has not been directly measured in any other work. Some studies have partially employed the Arnstein ladder for measuring citizen views of their current of relationship with government. For example: the finding in Lebanon that the overwhelming majority of participation experienced by citizens was of the 'inform' variety [35]; or how the type of engagement used in water shed management affected citizens' assessments on the Arnstein ladder [36]. In light of this we are forced to review work that approaches parts of the gap phenomena in different ways.

Examples can be found of studies that have tried to understand the desired relationship of citizens with government without using the Arnstein Ladder. For example, using a Likert scale between 'direct democracy' and 'unfettered decision-making power for elected officials', US citizens were found to have an average rating for that was around halfway between these endpoints [11]. If we transpose their scale to one that approximates a 6 rung Arnstein ladder from 'citizen control' to 'informing, this preferred 'midpoint' is equivalent to that of 'partnership'. From similar vantage points, other studies have investigated citizens' preferences through comparisons between direct democracy, elected representatives and technocratic rule in various countries such as Finland [37], Denmark [38] America [14, 39] and Spain [40]. The results were often indeterminant and contradictory with preferences that were contextual and seemed to straddle all three modes. This could be explained by a desire by citizens for partnership with experts and politicians when it comes to governance rather than the dichotomous frame imposed in the surveys. If so, this supports the citizen expectation part of the Arnstein gap.

As to the matter of whether expectations are being delivered upon the broadest evidence comes from one of the largest surveys of citizen participation in government in a meta analysis of 100 cases citizen engagement of in the developed and developing world. On the one hand it showed a preponderance of positive effects of citizen participation in government, but on the other, that formal governance processes represented the smallest part of this [41]. This adds to the evidence that there appears to be a gap between the participation government currently offers and the relationship citizens seek- and they will find it outside government if necessary. If this gap is 
indeed widespread then can interventions be made to close it through the actions of government?

\section{Implementing a participatory intervention - deliberative democracy in Greater Geraldton, Western Australia}

Prior to staging a participation intervention the presence of the Arnstein gap would first need to be detected in our Australian case study. To determine whether the features of the Arnstein gap would be replicated in the Australian context, an Arnstein survey of citizen expectations and experience of participation in government initiatives was sent to 2000 randomly selected residents of the Greater Geraldton city-region. This is an area of $12,626 \mathrm{~km} 2,430 \mathrm{kms}$ north of the capital city of Western Australia (WA), Perth, with population of around 40,000 . The survey showed a community preference for a partnership and an experienced reality between informing and consultation. These research results closely replicated the USA Arnstein gap results.

This research then focused on understanding whether the Arnstein gap could be narrowed if citizens experienced a different form of participation than they were getting - one that aimed to deliver their preferred 'partnership' relationship. Partnership, was defined as a relationship between two or more parties that cooperate together, sharing power by using their mostly equivalent levels of influence (or claims to influence) to achieve a common goal. ${ }^{1}$ Partnership is particularly distinct from other rungs on the ladder (e.g. manipulation, informing, consultation, delegation) which have asymmetries in shared power distribution [20]. Although unstated in the original Arnstein ladder article, we assume that the cooperative nature of the partnership relationship was also important (i.e. not competitive or ambivalent), and that it is directed toward some good that was common to the parties. Given this understanding of partnership, deliberative democracy appeared to be a good fit for the planned intervention because of its relationship between government and citizens.

Deliberative democracy differs from other forms of democracy in the manner in which it confers political equality. To explain - representative democracy confers equality through an equal vote to each citizen; participatory democracy confers it by equal opportunity for involvement; and direct democracy confers it through single votes directly on issues. Deliberative democracy realises equality through a communication method that privileges the strength of arguments and the equal ability of participants to justify and reflect on those arguments [42]. The collective outcomes of these deliberations influence policy development or decision-making via common will formation for the society as a whole [43]. This, political equality in service of the common good appeared to be a good fit intervention at the 'partnership' rung on the ladder. This was especially so since this intervention incorporated cooperation within and between government officials, subject matter experts, and citizens. Equally advantageously were deliberative democracy's well developed, and proven technologies and tools for generating and measuring collaboration and deliberation [10,44].

Our case study intervention was part of a four year action research program (2010-2014) piloting deliberative democracy in the City of Greater Geraldton (CGG). Numerous deliberative democracy initiatives, detailed elsewhere [45], aimed to change the dynamics of interaction between government and citizens to help develop a more sustainable future for the city-region. Two innovative participatory budgeting initiatives conducted over 2013-2014 were examined specifically to understand participation dynamics. Participatory Budgeting (PB) is a form of public budgeting which has grown exponentially over the last 30 years, where citizens allocate a budget according to their values and criteria [46]. This usually involves citizen groups developing options and the broader public voting on them, with the top priorities within the budget being funded and implemented. Another form of $\mathrm{PB}$, now known as 'The Australian PB' [47] is characterised by randomly selected and stratified juries (or 'mini publics' [48]) meeting over 5-8 weeks to deliberate how $100 \%$ of a budget should be allocated. This is distinct from the usual PBs which allocate around $10 \%$ of a budget $[49,50]$.

The CGG PB program consisted of two separate, descriptively representative mini-publics ${ }^{2}$ of randomly selected residents of the City stratified by age, gender and geography to match official census data. The first mini-public was tasked with prioritising over \$AUD70 million of infrastructure spending over the next 10 years for the local government. Called the 'Capital Works Panel', its 28 citizens met for four and half consecutive Saturdays to create criteria to compare and rate 130 infrastructure projects using a deliberative form of a multi-criteria analysis technique. The second mini-public was asked to set the operational budget of the local government of around \$AUD70 million for the next financial year. Called the 'Range and Level of Services Panel' its 35 citizens met for eight consecutive Saturdays to make recommendations on whether service areas should be increased, held constant or decreased, assessed according to a values-based process [17]. At the conclusion of both PB Panels, their recommendations were submitted to the elected Council [51, 52]. The Council endorsed the outcomes of both PBs, using the recommendations to form the budget of the following year as well as the infrastructure program for the following decade. Given the tough economic situation and a contentious history [53] some of the difficult decisions 
made normally would have resulted in public and elected official dissention. This did not occur - not only did the Council accept the decisions, so did the public ${ }^{3}$ $[2,54]$.

\section{Data gathering and methods}

Having located our case study parameters, we now turn to our approach to understanding the case study. A mixed methodology of quantitative and qualitative methods was used to assess and explain participant and administration staff attitudinal changes, as well as participant evaluations of the quality of the deliberation processes. The Arnstein ladder tool was used in a similar manner to previous studies in developed countries to assess the dichotomous power disparity within the citizen-government/administration relationship. Using Dryzek's criteria for the appropriate use of surveys in this context [13], causal generalisations were not sought from this tool. However short explanations on each rung of the ladder were used to ensure common comprehension and increase the chances of repeatability. To counter some of the other weaknesses of survey tools highlighted earlier, semi structured face-to-face qualitative interviews with randomly selected participants were also implemented to add confirmatory and explanatory power. Interviews were conducted with 25 of the 63 panellists, 5 of the 15 elected Members of the Council and 11 of the staff involved in the planning and execution of the panels. This data gathering was followed by direct observation of participant and staff daily staff debriefings, document analysis, and observation of the elected council budget meetings.

The same survey that was administered to the wider community was also given to the randomly selected $\mathrm{PB}$ Panel participants on the first day of the Panels (prior to the beginning of the Panel activities), at the midpoint of the Panel sitting days, and on the final day at the end of the Panel deliberations. Participants in both the community surveys and the PB Panel surveys closely matched the demographics of the region in terms of gender and geographical distribution but with fewer youth than expected from census data [51, 52]. Figure 1 shows the customisation $^{4}$ of the ladder that was used in the survey administered to the community and participants with the questions "CURRENTLY, How do you feel the City of Greater Geraldton treats its residents?" and "IDEALLY, How would you like the City of Greater Geraldton to treat its residents?" The original Arnstein ladder is placed alongside to enable easy comparison.

Additional information was gained through quantitative participant surveys, filled out after each deliberation day, measuring dimensions of deliberativeness and the usefulness of the processes. An Independent Review Committee (IRC) of external community members, including a lawyer and other respected citizens, oversaw the process to ensure its fairness, transparency and egalitarian nature as well as comprehensiveness and lack of bias in the information presented and available. Members of the IRC met with the participants after each deliberation day without any of the organising/facilitation team present. This gave participants a chance to openly discuss and evaluate the independence, fairness and validity of the process without outside influence. Issues raised were discussed and documented in debrief meetings.

\section{Quantitative results: presence and narrowing of an Arnstein gap}

Figure 2 shows the mean participation levels (both ideal and currently) on a scale from 1 (manipulation) -8 (citizen control) for the PB participants over the course of their workshops. The CGG Community results with those of US participants from Bailey et al. are shown adjacent for comparison purposes.

Four comparative conclusions were elicited at this stage

1. The WA city-region's community assessment of the current level of participation with their government very closely resembled the findings by Bailey et al. [33] in the US. However, the ideal level of participation for the Geraldton community was slightly lower than the US ideal (5.7 vs 6.1). This difference could be explained by a combination of some measurement variation as well as selection bias in that only potential respondents willing to participate in transport planning were included in the US sample. Such willing volunteers could have had higher ideals for their relationship with government than the broader community surveyed in Greater Geraldton. This rationale is supported by other research demonstrating the altitudinal differences between participants in engagement activities and the wider community $[55,56]$.

2. The panellists at the beginning of the participatory budget process were a close attitudinal match to the broader community on their assessment of the current participation level, but they had a higher assessment of the ideal level (6.4 and 6.2 vs 5.7). This result too, could be explained as a form of selection bias. By accepting an invitation to a PB, panellists may have higher ideals of participation than the general population. Certainly, all interviewees indicated that the partnership level of participation was the preferred relationship with government.

3. The process of being involved in a highly participative intervention did not significantly shift participants' assessment of the ideal level of 


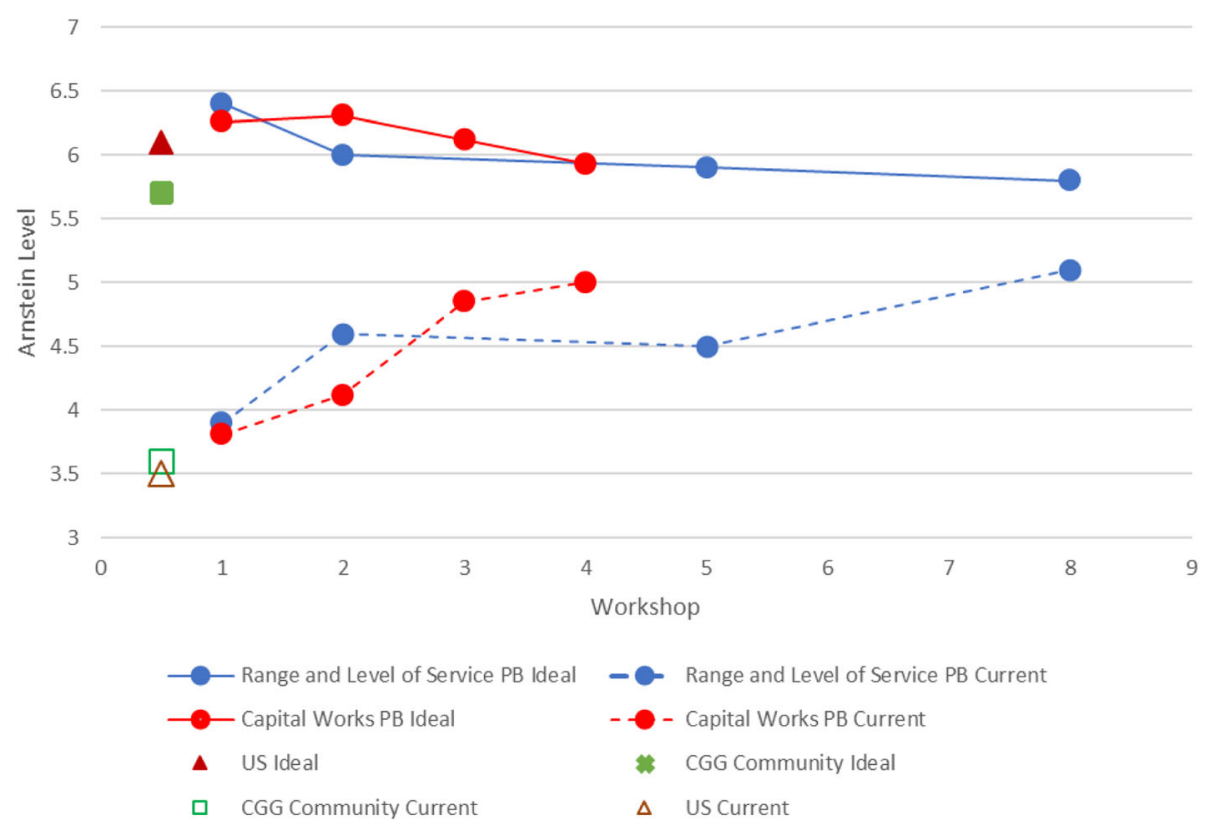

Fig. 2 Arnstein Gap data

participation as "partnership" - this attitude moderated and stabilised, if anything. This seems to mitigate against the possible thesis that the citizens' nomination of an ideal participative relationship was a normative aspiration, and as such, was naïve, ill-informed and would likely change if citizens were subjected to the rigours of disagreement and the responsibilities of a true partnership relationship [11].

4. The Arnstein gap decreased by around $2 / 3$ rds over the course of both PB's even though they ran for different durations.

These results indicated that the Arnstein gap applied in Australia and America, across regional areas and over time, ${ }^{5}$ and that participatory interventions could potentially narrow the gap.

\section{Qualitative results: partnership relationships between citizens and government}

Despite the opportunity to select greater control (citizen control or delegation) respondents preferred the idea of partnership both before, during and after the PB's. This preference was further probed through interviews and survey questions on the 'design for partnership' of this intervention. ${ }^{6}$ What generally emerged was a desire for, and approval of, a relationship where political equality was acknowledged, and respect was shown for each party's skills and strengths - all underpinned by intentions to work toward a common goal. Additionally, the interviews showed that panel participants developed and desired similar partnerships between panel members.

There were several roles involved in the notions of partnership - participants, local government staff, elected representatives and the small Curtin University team. Participants were the deliberators - involved in small group discussion, cross examination of expert witnesses, problem resolution and creation of recommendations. Local government management was responsible for the overall organisation and the provision of information making available all budget information required by panellists in easily understood ways including written formats, presentations and verbal cross examination. Other administration staff were trained as small group facilitators, themers and scribes. Elected members were allowed to observe but not intervene. The Curtin University team researched the initiative and helped to design and orchestrate it.

To understand what participants meant by 'partnership', we looked for indications of what we called staff 'competence' and 'benevolence' in interviews. Benevolence referred to the panellists' belief that the intentions of the staff were oriented in the same direction as the panellists' intentions - not individually, but toward what participants understood to be the common good of the community, in their roles as descriptive representatives of that community. To probe the concept of partnership as shared power, we also examined beliefs about the competence of the staff in their jobs serving the community. This competence belief 
acted as a proxy for the ability of the local government to contribute to the common goal of the panel.

Panellists universally indicated during interviews that they regarded the government staff as highly competent in their areas. For example:

"It was very interesting to find out what the Council was doing and mind boggling the amount of money they have to juggle around, and the amount of projects they have to deal with ... I went in there thinking probably the same as everybody else - 'What is Council doing with rates money?' And I came out thinking, 'Well, they are doing a pretty good job actually."

"I think they are very competent - they are far more competent than I believed they were. ... the general consensus of their competence is not as high as it should be. People don't understand the level of services and the effort required for that level of services."

There was also consensus that they were acting benevolently in the best interests of the community both generally and in undertaking the PBs.

"... I understand how hard they work trying to make it all good, including the fact that they started this in the first place and they were willing to give it a go."

"The people at the Council, the Directors and their passion, their interest, and their willingness to give it a go, sort of makes you feel you are in fairly good hands considering the reputation they have had."

"I do believe there are genuinely committed to making this place a better place to live but some the ways they go about that aren't achieving that goal."

One panellist at least was aware that the assessment of competency was also occurring from the other side of the relationship.

"I think they thought the bottom drawer would be where it would go, and that would be the end of it. I don't think they appreciated the fact that if we come out with something silly here, ... they are going to look at it and say - 'This is all that's coming out? What we have spent all the time and money and effort on? Don't worry about it in the future'. And that would be sad. It's important that people don't just go in there with those axes to grind."

If there was a partnership relationship between staff and residents, it would also be expected that staff would express similar assessments of benevolence and competence toward the citizens. This was particularly so, since the Arnstein ladder surveys of staff showed their ideal participation rung was also partnership. ${ }^{7}$ The staff interviews noted participant competence, though they highlighted the difficult path for both staff and participants to communicate better to achieve mutual understanding. As an infrastructure staff member mused;

"When they first came in and we gave them a brief on what they had to do - they just didn't seem to get what we were on about. I thought, "Jesus, if this is what we in for over the next few weeks, we're in strife". But then when we started to get the message across ...".

And as a participant commented:

"It was probably about week 4 I think, when I felt we started to click more. The first few weeks were trying to get everyone to dance around the same campfire. And then when that started happening - you could see it in every table you went to. They were like - 'this is great, this is great', and we started to smash through it."

The overall conclusion by the staff interviewed was that the citizens were competent, and that this was the result of intense work by both parties. As a manager summarised;

"They are but you have to invest time. You can't expect that people have that competency off the tops of their heads. It's unrealistic. As long as you have realistic expectations that people need support, advice, information, whatever in order to lift their level of competency - it's there."

Most staff also thought participants had the common goal to act in the best interests of the wider community:

"I think so. Yeah. Given the questions they were asking, they certainly were taking themselves out of it and looking at the broader picture."

"If you continually remind them that they are here to make decision for the whole community and not just for themselves and you put them in the space where they continually hear from other people and opinions and backgrounds, they do grow. I've seen that."

This assessment of benevolence was also supported by examining the list of prioritised projects produced by the Capital Works Panel which placed minority interests such as outlying settlements, mobility impaired groups, 
and youth near the top of the list [51]. As one manager remarked.

"Key moments would be when that clicked into place how important it was for them to come up with their own values ... because there was so much passion in the room. When they were done, and Mullewa came up really high, and mobility access came up really high, even though the group wasn't all disabled or in wheelchairs."

One staff member summarised this partnership relationship as follows:

"Both panels agreed: You guys are the experts. You should know why and how and what's important, that's why it worked. It needed to be for informed decision-making. (And) ... we can learn from the community what's important. What they value, what they want. They can help us prioritise things."

\section{Qualitative results: partnership relationships between citizen participants}

Interviews also showed the existence of partnership relationships between the panellists. Evidence of benevolence included expressions of their fellow panellists being oriented positively toward each other as well as the greater community. Participants described the attribute of competence of their fellows differently to staff, though. For the staff, competence involved the volume of knowledge and experience relevant to local government operations and infrastructure. For participants, competence involved their ability to perform their tasks of representation and deliberation well enough to achieve the goal of allocating the budget for the common good.

The following quotes referred to these competencies and in particular - as the staff also noted - the time it took to get there:

"I think it was a lot to absorb. We knew why we were there, but I had to get my head around how we were going to do it. Some people got it straight away some people didn't get it right to the end. I personally found the majority of people found it was around that week 4."

"There was so many people, so many different areas at times, it was really tough - we all had different opinions. We did have to get to know each other then get to know what we were doing. As the weeks went by it got easier to fall into the groove and start doing what we needed to do."
After this period of orientation and as more effective group dynamics evolved, participants became confident in the quality of their recommendations and this was reflected in daily surveys of their deliberative capacity. Most participants rated highly the quality of their deliberations including neutrality, access to information, ability to hear and be heard and representativeness of results. [51, 52]. Their sense of competence was also reflected in the interviews:

"Nearly every day we found things really interesting because 6 or 7 people's views were thrown in. You may see things in a certain direction but after some explanations you may see it in 2 or 3 directions and you have to work out an amicable solution."

"There was a few times there where they said 'oh I didn't think about that'. That makes me happy, at least they were listening. They may not change but at least they have heard the argument for the other side."

“... we just all seemed to get it, and we all seemed to click and it didn't matter if we had difference of opinion, we listened well to each other, we explained well and then we reached an understanding and agreement and then moved onto the next thing."

On the subject of benevolence - whether their fellow panellists were acting in a manner that would benefit the broader community beyond their own narrow interests - the majority of interviewees found such attitudes prevalent;

"I think everyone had good intentions. Despite how they started I think by the end of it they did want it to be better."

"It's a good way to have a say in what's going on as long as that's always tempered by - you are here as a representative. At those meetings, I brought up things that I personally don't agree with. But that being said, I know that a lot of my friends and people at work do. So, I still have my view but I go 'these people do have some good points, maybe I will include them in what I am doing'. It's about getting the best outcome for everybody. Not just 'ah well I don't use the pool so shut that down"'.

As noted earlier, the presence of final recommendations that gave preference to minority interests also reflected decisions made for the common good which gives additional support to claims of participants' benevolence. 


\section{How the partnership relationship influenced both the process and outcomes}

The data showed a holistic sense of partnership between participants and with the government employees they interacted with. Partnership was characterised by a belief in the other party's ability to do their job (provide expertise and information, or deliberate and represent the community) and a belief in the other party's intention to act in the best interests of the whole community (either in a role as a government 'expert' or a participant descriptively representing the community). Two events that unexpectedly occurred during the deliberations demonstrated in a concrete manner how the presence of these partnership relationships influenced the PBs. The first incident highlighted a break-down in the partnership relationship between panellists; and the second involved a reinforcement of the power sharing relationship, between participants and officials.

The first example occurred during a session which the Range and Level of Service Panel held with the broader community to get feedback on the panel's preliminary recommendations on the operational budget. As part of a community event to get that feedback several panellists volunteered to outline the Panels' recommendations on various areas in the budget to the public meeting. Without warning, one of the panellists, himself a property manager, presented the Panel's recommendations on property management to the public in a way that reflected his/developers' interests rather than the position the Panel had recommended - which was diametrically opposed. All panellists interviewed expressed various levels of dismay and outrage at his behaviour. Following this incident, panellists met and decided to make a complaint to the IRC that was overseeing the initiative. The IRC researched what had transpired, speaking to panellists, staff and the Panellist in question, who, they determined, had indeed misrepresented the Panel's views to the community. After being given an official verbal warning about such behaviour, panellists observed that the Panellist in question was much restrained and apparently chastened in subsequent panel deliberations. This one Panellist's failure to live up to the relationship expected of him - to act in the best interests of the panel and the wider community, highlighted the strength of the partnership relationship that had developed between panellists. Even so, this misdemeanour did not exclude that panellist entirely from the realm of the relationship. Notions of fair play and equal access still prevailed, as the following quote indicated:

\footnotetext{
"It wasn't a fair representation. That sort of thing divides the group ... all the surveys that had been done didn't want that, so then he goes and puts it out there ... It was really disappointing and heartbreaking
}

when he did that. Afterwards, he happened to be one of my teams on the last day and luckily enough he had lost his voice a little on that day. Which I thought was a blessing in disguise, but then in the same token he had things that he wanted to vote for but because he had lost his voice nobody was listening. So I did actually say, 'Hang on guys, I think XXXX is trying to say something' a few times because it still needs to be fair hearing - but gosh, I was so pee'd at him."

The second example portraying the seriousness of the partnership relationship occurred during the Capital Works $\mathrm{PB}$, this time involving panellists and officials over the issue of acceptable rating criteria. Participants developed a values-based set of criteria that was used as a rating system to consistently and fairly compare disparate infrastructure projects (e.g. runway extensions and youth centres). The idea of using community values to create rating criteria was selected because of its ability to enable the prioritisation of projects based on different but equivalent values. This design element was based on the concept of "public values pluralism", where "nearly all controversies boil down to choices among competing values" [17]. This competition between competing values is particularly pertinent in budgeting where constrained resources are being allocated amongst valuable activities. The panellists then used the rating system to create a prioritised list of projects. This process strengthened the power sharing aspect of the partnership, an opportunity potentially missed if the government had been left to rate the projects.

The Panellists' criteria were generated by agreeing on what they valued most about living and working in the city-region. However, the City CEO, preferred management's more standard criteria of economic, environmental, social, cultural and governance pillars. The Panel discussed this and determined to stay with their own criteria. The City management group then independently rated all the infrastructure projects according to their standard criteria. Interestingly, though the final lists of infrastructure priorities developed separately by the City 'experts' and the Panel community members had some differences, they were not significantly different. Since there were now two very different rating systems and something of a stand-off between panellists and City administration about the two systems, the panellists came up with their own way to resolve this. They collectively decided to acknowledge the expert system in their final Report to Council, recommending that a equally weighted combination of the two systems be adopted. Their justification was that although they fully supported their own system, they recognised that City officers had experience, skills and knowledge that made their rating systems valid as well. ${ }^{9}$ This recommendation was accepted by the 
elected officials and the City administration. This clearly reflected the partnership relationship that had developed between all parties, one that acknowledged the limits of the panelists knowledge, but the equal importance of community values, the expertise of the local government professionals, and the benevolence of all parties.

As a final example of the partnering relationship, when participants were asked "What analogy or metaphor would you use to describe your experience?" answers often reflected their acquired competency; "... like my head exploded into a whole heap of jigsaw pieces and then putting it back piece by piece over the weeks until I have a whole head again ..." or "It was like the sun coming out after the clouds. You are in the dark and now it is light." or similar metaphors such as emerging from a tunnel or looking beyond a screen on which shadows play. Other responses spoke to the notion of benevolent common goals "... like a football team; having the team and switching positions around and still going for the win." or experience in military units. In these images we find succinct analogies of the relationship of partnership highlighted by the Arnstein Ladder and the associated social learning $[25,32]$.

\section{How the intervention created conditions for partnership}

Deliberative democracy was selected as the intervention to determine if the Arnstein Gap could be reduced because of the fit of its principles and techniques with creating partnerships between panellists and with government. The specific design and process elements of a deliberative democracy initiative were not assessed as to their precise influence on the Gap. However, based on our experience and the literature $[26,57]$, the following features were likely influential:

- An egalitarian deliberation environment was created through small group, facilitated deliberation between participants with diverse viewpoints, where equal opportunities to speak and listen in respectful discourse were encouraged. An innovative software platform enabled all views, including minority viewpoints to be acknowledged and considered by the room as a whole.

- Priorities were determined through the collective development and application of values-based criteria in a multi-criteria analysis. This reduced the dependence on those with field specific knowledge and shifted discussions from contentious debate to a deeper understanding of others' values and viewpoints.

- Participation was based on representativeness, i.e. the stratified randomly selected participants understood that they were responsible for representing their community. Participants were unencumbered with the need either for 're- election' or for self-aggrandisement and could act benevolently in the common good. Though intransigent beliefs that could impede competent deliberation were present, they were random rather than systematic.

- The focus on reason-giving communication enabled greater understanding of differences; and the search for common ground rather than a simple vote that invariably creating winners and losers. This generated space for opinions to shift in the light of data and arguments, rather than stagnate or solidify around early attitudes and positions that voting can precipitate.

- The agenda design maximised the conditions for competent decision-making by providing diverse ways to present information and regular Q\&A sessions to enhance the whole group's understanding and level the playing field between participants, government officials and other experts.; This was combined with adequate time for reflection to enable careful consideration of recommendations and their justifications as well as evaluation.

- Operational features signalled the importance of the panellists to the CGG. They were provided comfortable, accessible, respectful environments and scheduling that maximised participation levels and continuous attendance. All panellists were paid per diem or stipend contributions; given access to childcare and travel assistance if needed;; as well as official and public recognition of participants' time and effort.

Before moving from this discussion of the importance of deliberative democracy as an intervention we should acknowledge the possibility that the citizens are being unduly influenced by the government they are in relationship with. Some authors have been concerned that the expertise imbalance between government officials and citizens can lead the citizens to unduly defer to the officials and be less critical, than say advocates and civil advocates [58]. In this case the partnership relationship would be a façade with subtle control in the hands of the government because of this uncritical citizen deference. Considering what is now understood about the emotional-rational nature of human cognition and deliberation we do not doubt that such deference is present and participant interviews indicate a respect for government expertise. It is also true the nature of partnership implies a mutual respect by both parties of the competence and benevolence of the other compared with the mutual suspicion of competitive relationships. The question then, for partnership relationships is whether the degree of deference is undue and uncritical. In our case study there doesn't seem to be much evidence of this 
excessive dynamic being present. Certainly, the lack of deference by the panellists to rating system of the CCG executive team compared to their own does not support the idea of excessive deference. Further independence can be found in recommendations of the Range and Level of Services Panel [52] which included suggestions for specific service improvements in all of the City's operations. These recommendations fly in the face of explicit instructions from the City executive team not to provide such suggestions and stick to general suggestions of increase, decrease or maintenance. Finally, we have the certification of the IRC in their final report of their daily monitoring of the workshops that the process was fair and unbiased.

In attempting to explain how this real possibility of 'administrative capture' was avoided, we propose several factors that help balance critical review and emotional relationships. At a theoretical level the process was helped by the selection of deliberative democracy which in principle insists on a critical cycle of reflection and justification between the parties. At a process level, the nature of the $100 \% \mathrm{~PB}$ was primarily about the allocation of scarce resources along community value lines rather than the questioning of a narrower policy positions or re-evaluation of social norms that often concern citizen juries. We believe the role of advocates in these more reflexive policy spaces is much important than in this strictly budgetary space. Particularly in this case where a uniform rating system put values-based criteria at the centre of decision making rather than expertise in particular area. Finally, at an operational and design level, critical reflection was encouraged by the built-in diversity of random group which hedged against the possibility of groupthink and deference. It was also helped by the length and iterative nature of the cross examination of City staff, where the initial presentation of information by staff was followed by room level and table level questioning and justification of the staff by participants. This occurred iteratively over several weeks to allow ongoing critical review as panellists knowledge and experience grew.

\section{The Arnstein gap and the role of trust}

Over the course of each $\mathrm{PB}$, this deliberative democracy intervention notably reduced the Arnstein gap between participant expectations and experience. This could have implications for increasing trust between citizens and government, especially when we consider the following three observations.

Despite best efforts to create a partnership relationship the current level did not reach ideal participation and the gap still remained. We assume that citizens assessment of the current level of participation is not an isolated process that is disconnected from history and context. The remaining gap then, may represent a distrust of the intentions and competence of government based on this past history and context. This manifested in interviews with Panellists expressing great hope but no certainty that a partnership relationship would continue. Hence, it's unlikely then that any single initiative could overcome the residual effects of past relationships with a local government [53], nor overwhelm the other demographic and attitudinal factors that also affect trust [38].

We also observe that if citizens were so desirous of a partnership relationship with government, then surely they would likely flock to such deliberative democratic opportunities like these PBs. However, the low recruitment rates from random lotteries to participate in such initiatives show the opposite response [59]. This pattern was also reflected in the response rate to invitations to participate in these PB's, which were below 20\%. However, this figure contrasts markedly with the overwhelming satisfaction and willingness of those who did participate to be involved in such events again [51, 52]. We draw on the limited research on low recruitment rates to explain this discrepancy as a combination of personal factors such as availability, competency and self-image, and a distinct aversion to 'politics as usual' [56]. That is, citizens are hungry for a partnership with their governments but are suspicious their time will be wasted with shallower interactions.

Finally, we observe that Fig. 2 shows a relatively large increase in the assessment of current participation after the first workshop in both PB's and a continuous improvement in this assessment until the final workshops. It doesn't appear this was due to improvements in deliberative conditions over the course of the panels, as deliberation indicators were rated consistently highly throughout both PBs, nor is it solely due to the sheer length of time spent as an 8 week and 4 week process both narrowed the Gap roughly the same amount. Based on our observations and specific comments from interviewees, the initial step improvements came from the deliberative democratic design features described above that were implemented from the first workshop. This immediately and concretely demonstrated the partnership nature of the PB's and was followed up with gradual reinforcement of the partnership relationship as the process unfolded and trust developed in participant and staff competence and benevolence..

Trust appeared to be integral in each of the above observations about the effects of participation in government on citizens. Other researchers have also noted a strong linkage between participation, trust, and their correlates of benevolence and competence [25, 60-62]. This leads us to wonder if citizens who are experiencing an unsatisfactory participation relationship with their 
government could be reflecting this in the growing distrust of government that has been documented across many western democracies [63]. If this is the case then it would take some time for citizens to accept that a shift to true partnership was authentic -hence the pattern of slow shrinkage of the Arnstein gap observed over the workshops. This caution would tend to persist even after an authentic partnership experience and manifest as an incomplete convergence of the ideal and current ratings at the end of the PBs. The citizens' unwillingness to participate in mini-publics would also be hampered by mistrust - the lack of equality and civility evident in 'politics as usual' would not engender citizens' trust that a participation process purported to be a partnership would actually be so.

This would indeed be ironic; if the gap itself created a negative trust feedback loop that made it more difficult to 'close' the gap. On the one hand, these research results offer hope that such a 'vicious cycle' could be mitigated by exposure to 'politics-as-unusual'. On the other, creating a 'virtuous cycle' of public trust would require consistent, ongoing partnership relationships with government.

\section{Conclusion and future work}

The existence of a gap between what is expected and what is received inevitably will lead to dissatisfaction and distrust. This is equally true of a service, a good, or a relationship with government. Such dissatisfaction and distrust undermines the effectiveness of governments in taking actions over the long time scales and of the flexible nature needed for the wicked problem of sustainability [2]. The research carried out in Greater Geraldton, WA, reaffirmed the USA findings that the relationship citizens preferred with government was partnership, but what they experienced was far less empowered; more like being informed or consulted. With this phenomenon likely to be widespread, a citizen participation intervention was devised - two deliberative democracy initiatives in the form of Australian PBs. The results showed that over the duration of each initiative, the gap between public expectations and what they experienced was reduced. Additionally, it provided insights into the nature of citizens' preferred relationship of partnership, including the desire for cooperation with government on the basis of common interests and mutual competence [39].

This research has led to further questions that will maximise the usefulness of these findings including:

- What is the generalisability of these finding beyond this case study and that in the USA? The case study method enabled us to take substantial strides forward in understanding the sort of intervention likely to reduce the Arnstein Gap and we strongly believe these apply in most western nations. However, to be more useful to sustainability practitioners and governments it will need to be generalised through further research in other places at other times.

- What is the effect of other sorts of interventions? This case study applied a particular deliberative democracy method, specifically, two Australian style PBs, with different participants, at different times and on different budgets topics. Both initiatives resulted in closing the Arnstein Gap. Could other interventions that are targeted to local sustainability goals also reduce the Gap and by how much?

- What is the ability of such initiatives to be scaled out more broadly so as to impact the broader population and sustainability issues that don't respect bureaucratic borders? This question of scaling of deliberative democracy has proven to be problematic [10]. Though some progress has been made [47], it has been a slow, iterative process.

- How important is an initiative's process design in creating a sense of partnership especially when compared with other variables of importance, (e.g. the salience of the topic, numbers of participants involved, whether deliberations are face-to-face or online)? This case study confirms the idea that the design of public participation is at least as important as the level of participation [35, 64]. Additional studies are needed to deeply understand design questions like; How much participatory design does it take to close the Gap per gradation of the Arnstein scale? Or what are the cost benefit trade-offs of closing the Gap in a world of limited resources devoted to working toward sustainability?

Finally, this research highlights a further significant line of enquiry. Arnstein suggested in her original article that the partnership level requires power to be taken from the government, and historically, this has been the case [20]. However, this implies an inevitably adversarial approach between the people and their governments that undermines sustained partnering. Her contention has not been supported by our experience nor our understanding. When partnership has been achieved, the sharing of power in the service of the common good has been predicated on trust between both parties to the relationship - citizens and government. This research offers a potential way forward to increase citizens' worryingly low levels of trust in their democratic governments but it will require both parties to extend trust to each other. Governments developing 'business as unusual' partnering relationships with their citizens will have to trust that given resources and the right 
conditions citizens can competently act for the common good. When citizens extend that same trust to their governments, then partnership can become 'business as usual'. This could not only reduce the gap between the participation citizens expect and what they experience, but potentially reduce distrust, empowering coordinated action on the sustainability challenges facing all of us.

\section{Endnotes}

${ }^{1}$ Later in this article, we examine evidence of participants' understanding of this concept.

${ }^{2}$ We define a mini public as a broadly representative sub group, demographically mirroring an affected population, that engages in structured and facilitated deliberation toward an influential end.

${ }^{3}$ For further detail on this projects' decision-making in the interests of sustainability, see (Hartz-Karp and Weymouth, 2018) and (Weymouth and Hartz-Karp, 2018).

${ }^{4}$ For comparability, we applied a similar version of the ladder used in the US with some minor differences. In that study, the questions were framed around participation in 'transport planning and design processes', and the questions were asked in reverse order. Also, the transport planning participants responded with electronic keypads with the results being immediately fed back to them, as opposed to filling out paper surveys.

${ }^{5}$ We would caution generalising this conclusion to include nations where institutionalised democratic government has collapsed, has become undermined by corruption (Choguill, 1996), or are in dispersed power relationships that would complicate the implicit dichotomy of the ladder (Tritter and McCallum, 2006).

${ }^{6}$ The interviews generally confirmed the patterns seen in the surveys and added explanatory value as hoped. This outcome went against Dryzek's expectation that in-depth interviews and surveys would be contradictory because of the reflective/non-reflective dichotomy of the interview/survey. We believe this was avoided because the interviews were used for explanatory purposes and did not require interviewees to strongly reflect on the participation aspects.

${ }^{7}$ Although not described here, Arnstein data was gathered for the citizen/government relationship preferences for the staff of the CGG. The results closely mirrored those found in the United States including the presence of a 'professional conceit' - a slightly higher estimation of the current level of participation when compared to citizens.

${ }^{8}$ Mullewa is a town $100 \mathrm{~km}$ from Geraldton with a population of around 600 .

${ }^{9}$ As we have seen above, if the citizens' participatory attitudes were oriented toward full control or alternatively, full deference to the experts, we would expect the Panel to either reject outright the City rating system (a veto equivalent to 'citizen control') or to abandon their own system (deference equivalent to 'Informing').

\section{Abbreviations}

CGG: City of Greater Geraldton; IRC: Independent Review Committee; PB: Participatory Budget; USA: United States of America; WA: Western Australia

\section{Acknowledgements}

The authors would like to acknowledge the contribution of an Australian Government Research Training Program Scholarship in supporting this research.

\section{Funding}

This research received no external funding.

\section{Availability of data and materials}

The datasets used and analyzed during the current study are available from the corresponding author on reasonable request.

\section{Authors' contributions}

Conceptualization, RW and JH-K; Methodology, RW and JH-K; Analysis, RW; Investigation, RW; Data Curation, RW; Original Draft Preparation, RW; Review \& Editing, RW and $\mathrm{JH}-\mathrm{K}$. Both authors read and approved the final manuscript.

Ethics approval and consent to participate

This research received Curtin University ethics approval RD-30-10. All participants consented to the gathering and publication of the data used in this publication.

Consent for publication

Not applicable.

Competing interests

The authors declare they have no competing interests.

\section{Publisher's Note}

Springer Nature remains neutral with regard to jurisdictional claims in published maps and institutional affiliations.

Received: 18 November 2018 Accepted: 21 March 2019

Published online: 18 April 2019

\section{References}

1. Lane MB. Public participation in planning: an intellectual history. Aust Geogr. 2005:36(3):283-99.

2. Weymouth R, Hartz-Karp J. Principles for integrating the implementation of the sustainable development goals in cities. Urban Sci. 2018:2(3):77.

3. Rittel HW. On the Planning Crisis: Systems Analysis of the "First and Second Generations". Stuttgart: Institut für Grundlagen der Planung IA, Universität Stuttgart; 1977.

4. Conklin J. Dialogue mapping: building shared understanding of wicked problems. Hoboken: Wiley; 2005.

5. Edelman. Edelman Trust Barometer 2017: Executive summary. https://www. edelman.com/executive-summary/. 2017.

6. Sen A. Development as freedom. New York: Oxford Paperbacks; 2001

7. Ober J. What the ancient Greeks can tell us about democracy. Annu Rev Polit Sci. 2008;11:67-91.

8. Carson L. Ignorance and Inclusion, Mr Jefferson, Might be Good for Democracy: United States Study Centre, University of Sydney; 2009.

9. Brandsma GJ, Adriaensen J. The principal-agent model, accountability and democratic legitimacy. In The principal agent model and the European Union. Palgrave Macmillan, Cham. 2017;35-54.

10. Mansbridge J, Bohman J, Chambers S, Christiano T, Fung A, Parkinson J, et al. A systemic approach to deliberative democracy. In: Parkinson J, Mansbridge J, editors. Deliberative systems: deliberative democracy at the large scale; 2012. p. 1-26.

11. Hibbing JR, Theiss-Morse E. Stealth democracy: Americans' beliefs about how government should work. Cambridge: Cambridge University Press; 2002. 
12. Thompson DF. Deliberative democratic theory and empirical political science. Annu Rev Polit Sci. 2008;11(1):497-520.

13. Dryzek JS. Handle with care: the deadly hermeneutics of deliberative instrumentation. Acta política. 2005;40(2):197-211.

14. VanderMolen K. Stealth democracy revisited: reconsidering preferences for less visible government. Polit Res Q. 2017;70(3):687-98.

15. Oliver A. Lowy Institute Poll 2018: Sydney Australia: Lowy Institute; 2018.

16. de Almeida HN. Critical reflections concerning the concept of participation in social intervention and research. Eur J Soc Sci Educ Res. 2017;11(2):293-300.

17. Nabatchi T. Putting the "public" back in public values research: designing participation to identify and respond to values. Public Adm Rev. 2012;72(5): 699-708.

18. Nabatchi T, Leighninger M. Public participation for 21st century democracy. Hoboken: Wiley; 2015.

19. Ross H, Buchy M, Proctor W. Laying down the ladder: a typology of public participation in Australian natural resource management. Aust J Environ Manag. 2002;9(4):205-17.

20. Arnstein SR. A ladder of citizen participation. J Am Inst Plann. 1969;35(4): 216-24.

21. Callahan K. Citizen participation: models and methods. Int J Public Adm. 2007;30(11):1179-96

22. Maier K. Citizen participation in planning: climbing a ladder? Eur Plan Stud 2001;9(6):707-19

23. Collins K, Ison R. Jumping off Arnstein's ladder: social learning as a new policy paradigm for climate change adaptation. Environ Policy Governance. 2009;19(6):358-73.

24. Choguill MBG. A ladder of community participation for underdeveloped countries. Habitat Int. 1996;20(3):431-44.

25. Hurlbert M, Gupta J. The split ladder of participation: a diagnostic, strategic, and evaluation tool to assess when participation is necessary. Environ Sci Pol. 2015:50:100-13.

26. Nabatchi T. A manager's guide to evaluating citizen participation. Washington, DC: IBM Center for the Business of Government; 2012

27. Nelimarkka M, Nonnecke B, Krishnan S, Aitamurto T, Catterson D, Crittenden C, et al., editors. Comparing three online civic engagement platforms using the "spectrum of public participation" framework. Proceedings of the Oxford Internet, Policy, and Politics Conference (IPP); 2014.

28. Fung A. Varieties of participation in complex governance. Public Adm Rev. 2006;66:66-75.

29. Carson L. The IAP2 Spectrum: Larry Susskind in conversation with IAP2 members. Int J Public Participation. 2008;2(2):67-84.

30. Hayward C, Simpson L, Wood L. Still left out in the cold: problematising participatory research and development. Sociol Rural. 2004;44(1):95-108.

31. Aylett A. Participatory planning, justice, and climate change in Durban, South Africa. Environ Plan A. 2010;42(1):99-115.

32. Tritter JQ, McCallum A. The snakes and ladders of user involvement: moving beyond Arnstein. Health policy. 2006;76(2):156-68.

33. Bailey K, Blandford B, Grossardt T, Ripy J. Planning, technology, and legitimacy: structured public involvement in integrated transportation and land-use planning in the United States. Environ Plann Part B. 2011;38(3):447.

34. Bailey K, Grossardt T, Ripy J. High-performance public involvement: frameworks, performance measures, and data. Transport Res Record J Transport Res Board. 2015;2499:45-53.

35. AbouAssi K, Nabatchi T, Antoun R. Citizen participation in public administration: views from Lebanon. Int J Public Adm. 2013;36(14):1029-43.

36. Ormsbee L, Hoover A. Stakeholder Engagement in Public Natural Resource Management. In: Ames DP, Quinn NWT, Rizzoli AE, editors. Proceedings of the 7th International Congress on Environmental Modelling and Software; June 15-19. San Diego: International Environmental Modelling and Software Society; 2014.

37. Bengtsson $\AA$, Christensen $\mathrm{H}$. Ideals and actions: do citizens' patterns of political participation correspond to their conceptions of democracy? Gov Oppos. 2016;51(2):234-60.

38. Coffé $\mathrm{H}$, Michels A. Education and support for representative, direct and stealth democracy. Elect Stud. 2014;35:1-11.

39. Bowler S, Donovan T, Karp JA. Enraged or engaged? Preferences for direct citizen participation in affluent democracies. Polit Res Q. 2007;60(3):351-62.

40. Font J, Wojcieszak M, Navarro CJ. Participation, representation and expertise: citizen preferences for political decision-making processes. Pol Stud. 2015; 63(1_suppl):153-72.
41. Gaventa J, Barrett G. So what difference does it make? Mapping the outcomes of citizen engagement. IDS Working Papers. 2010;2010 (347):01-72.

42. Dryzek JS. Theory, evidence, and the tasks of deliberation. In: Rosenberg S, editor. Deliberation, participation and democracy: can the people govern? London: Palgrave Macmillan; 2007. p. 237-50.

43. Gastil J, Richards RC. Deliberation. In: Mazzoleni G, editor. International Encyclopedia of Political Communication. Chichester: John Wiley \& Sons; 2016.

44. Chambers S. Deliberative democratic theory. Annu Rev Polit Sci. 2003;6(1): $307-26$.

45. Weymouth R, Hartz-Karp J. Deliberative collaborative governance as a democratic reform to resolve wicked problems and improve trust. J Econ Soc Policy. 2015;17(1):4.

46. Dias N. Hope for democracy: 30 years of participatory budgeting worldwide. Dias N, editor. Portugal: Epopeia Records; 2018.

47. Carson L, Hartz-Karp J, Briand M. Deliberative Democracy as a Reform Movement. In: Bächtiger A, Dryzek J, Mansbridge J, Warren M, editors. The Oxford Handbook of Deliberative Democracy. Oxford: Oxford University Press; 2018.

48. Ryan M, Smith G. Defining mini-publics. In: Grönlund K, Bächtiger A, Setälä M, editors. Deliberative Mini-Publics: Involving Citizens in the Democratic Process. Colchester: ECPR Press; 2014. p. 9-26.

49. Thompson NK. Participatory budgeting-the Australian way. J Public Deliberation. 2012;8(2):5.

50. Christensen HE, Grant B. Participatory budgeting in Australian local government: an initial assessment and critical issues. Aust J Public Admin. 2016;75(4):457-75

51. CGG. Particpatory Budgeting Community Panel 10 Year Capital Works Plan Recommendations \& Report to the City of Greater Geraldton (30 November 2013). http://www.cgg.wa.gov.au/sites/default/files/ 10\%20Year\%20Capital\%20Works\%20Community\%20Panel\%20Report\%20\%20Final\%20Draft_0.pdf. 2014.

52. CGG. Participatory Budgeting Community Panel Range and Level of Services Final Report (9 April 2014): City of Greater Geraldton. http://www.cgg.wa. gov.au/sites/default/files/Range\%20and\%20Level\%20of\%20Services\%20 Final\%20Report\%209\%20April\%202014_1.pdf. 2014.

53. ABCNews. Barnett criticises 'unacceptable' rate rise: ABC News; 2012. http:// www.abc.net.au/news/2012-10-25/barnett-criticises-unacceptable-rate-rise/ 4333798.

54. Hartz-Karp J, Weymouth R. Australian Participatory Budgeting. In: Dias N, editor. Hope for Democracy: 30 Years of Participatory Budgeting Worldwide: Oficina. Portugal: Epopeia Records; 2018. p. 403-22.

55. Neblo MA, Esterling KM, Kennedy RP, Lazer DM, Sokhey AE. Who wants to deliberate—and why? Am Pol Sci Rev. 2010;104(03):566-83.

56. Jacquet $\mathrm{V}$. Explaining non-participation in deliberative mini-publics. Eur J Polit Res. 2017:56(3):640-59.

57. Fung A. Survey article: recipes for public spheres: eight institutional design choices and their consequences. J Polit Philos. 2003;11(3):338-67.

58. Boswell J, Settle C, Dugdale A. Who speaks, and in what voice? The challenge of engaging 'the public'in health policy decision-making. Public Manag Rev. 2015;17(9):1358-74

59. Curato N, Niemeyer S. Reaching out to overcome political apathy: building participatory capacity through deliberative engagement. Pol Policy. 2013; 41(3):355-83.

60. Hooghe M, Marien S. A comparative analysis of the relation between political trust and forms of political participation in Europe. Eur Soc. 2013;15(1):131-52.

61. Christensen $T$, Lægreid P. Trust in government: the relative importance of service satisfaction, political factors, and demography. Public Perform Manag Rev. 2005;28(4):487-511.

62. Gustavsen A, Pierre J, Røiseland A. Participation or satisfaction? Examining determinants of Trust in Local Government. Scand J Public Admin. 2017; 21(3):3-16.

63. Edelmen. 2015 Edelmen Trust Barometer. 2015.

64. Evans M, Terrey N. Co-design with citizens and stakeholders. In: Stoker G, Evans M, editors. Evidence-Based Policy Making in the Social Sciences: Methods That Matter. Bristol: Policy Press; 2016. p. 243-61. 